\title{
Surgical Management of Combined Stab Injury of the Spinal Cord and the Aorta -Case Report-
}

\author{
Osman ŞIMSSEK, Cumhur KILINCER, Hasan SUNAR*, \\ Mustafa Kemal HAMAMCIOǦLU, Suat CANBAZ*, \\ Sebahattin ÇOBANOǦLU, and Enver DURAN* \\ Departments of Neurosurgery and ${ }^{*}$ Cardiovascular Surgery, Trakya University \\ School of Medicine, Edirne, Turkey
}

\begin{abstract}
A 32-year-old man presented with a combined penetrating stab injury of the spinal cord and the aorta caused by a knife wound in his back at the low thoracic level. The knife had broken, and part of the blade had been retained in the wound, passing through the spinal canal and into the aortic lumen. The patient was treated in two steps: the aorta was repaired by a thoracotomy, then spinal exploration was carried out through a laminectomy. Because of the tamponade effect of the foreign body, it was necessary to delay removal of the blade until vascular control had been achieved. Any sign of a penetrating body passing through the spine should suggest careful evaluation to detect any visceral injury, and multidisciplinary treatment should be planned.
\end{abstract}

Key words: aorta, penetrating wound, spinal cord injury, stab wound

\section{Introduction}

Penetrating traumas of the spinal cord or aorta are encountered occasionally in clinical practice, despite the protected position of these structures. However, combined injury caused by a stab wound is extremely rare ${ }^{4)}$ Here we report a case of successful multidisciplinary management of stab injury penetrating both the spinal cord and the aorta, and describe the clinical and radiological characteristics of this dangerous injury.

\section{Case Report}

A 32-year-old man was brought to our emergency department after being stabbed in the back with a knife during a fight, and suffering subsequent paraplegia. He was alert, hemodynamically stable, paraplegic, and anesthetic below the T-12 level. A $3-\mathrm{cm}$ midline incision in the low thoracic region had been sutured at the health center to which he had previously been admitted. Radiography and comput-

Received August 11, 2003; Accepted December 25, 2003 ed tomography (CT) showed a 10-cm metallic foreign body (broken knife blade) at the level of the wound (T11-12). The blade had passed through the vertebral canal and intervertebral disc, and reached the thoracic cavity. Careful evaluation of the CT scans revealed that $1 \mathrm{~cm}$ of the tip of the blade had remained in the aorta (Fig. 1). Administration of prophylactic antibiotics was started.

The patient was taken immediately to the operating room. The operation was performed in two steps by two teams: cardiovascular surgeons and neurosurgeons. A left thoracotomy was performed in the lateral decubitus position so that the site of the insertion was visible. There was no pneumothorax or hemothorax. Dissection was carried out around the aorta, dissecting the pleura. The blade was visible penetrating the aorta. The knife had clearly lacerated the posterior wall of the aorta, and the tip of the blade had actually remained within the lumen. The aorta was clamped proximal and distal to the insertion, further dissection was made, and the vessel was isolated. There was a 1-cm full thickness incision in the vessel wall. At this stage, the dorsal incision at the site of insertion was reopened, and the blade was easily withdrawn from the aorta and 


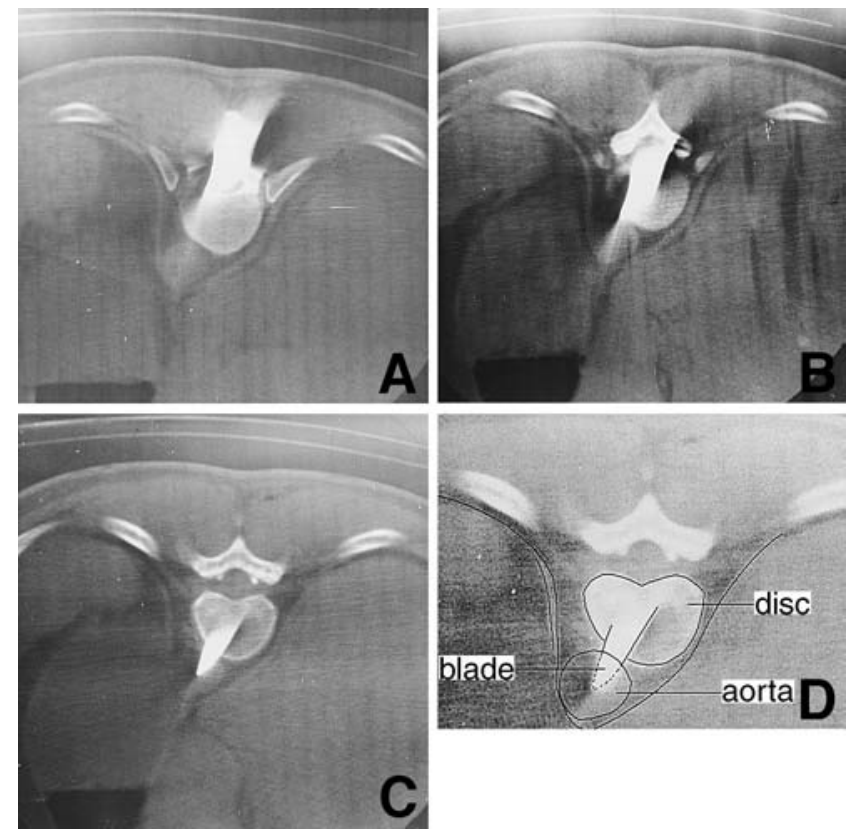

Fig. 1 A: Computed tomography (CT) scan showing the blade has penetrated the posterior elements and spinal canal. B: CT scan showing the blade has penetrated the spinal canal and intervertebral disc. C: CT scan showing the blade has penetrated the aorta. D: Schematic view of Fig. 1C.

thoracic spine. Primary repair of the laceration of the vessel wall was carried out with running 4-0 Prolene suture. The aortic clamping time was 10 minutes. After hemostasis was achieved, a thorax tube was inserted and the chest wall was closed.

During the neurosurgical step, the patient was positioned prone, and a midline vertical incision centered on the site of insertion was made. The incision of the blade was traced, and T11-12 laminectomies were performed. The dura and spinal cord had been divided, with only a few bundles spared on the right side. A spinal catheter was placed rostrally for drainage of cerebrospinal fluid, and the posterior dura was sutured. Closure was performed in a standard fashion.

The postoperative course was uneventful, no vascular problem was observed, and the patient was discharged home 2 weeks after the operation. He showed no neurological improvement, and one year after the operation, he remained paraplegic with no sphincteric control or sensory function below the T-12 level.

\section{Discussion}

Visceral injuries are associated with two-thirds of all penetrating spinal injuries suffered combat, but with only one-quarter of penetrating spinal injuries in civilians. ${ }^{2)}$ A recent study found $22 \%$ of penetrating spinal injuries occurred in the thoracic region, and 23 of 84 patients with thoracic penetrating injuries had associated visceral injury. ${ }^{7)}$ Gunshot wounds cause most penetrating spinal injuries, but stab wounds cause $7-26 \%$ of all penetrating spinal injuries, ${ }^{5-7)}$ and seem to be more frequent in thirdworld countries. ${ }^{3)}$ Stab injuries most commonly occur in young men, and usually involve the cervical and upper dorsal spine. ${ }^{5)}$ Penetrating injuries to the thoracic great vessels occur in $2 \%$ of cases of stab wounds to the chest, ${ }^{1)}$ but combined injury of both spinal cord and aorta by a dorsally placed stab is extremely rare.4)

Injuries to the great vessels are the most dangerous penetrating thorax traumas. The overall mortality of thoracic aortic injuries is higher than 90\%. ${ }^{1)}$ Most patients with aortic injury reach the hospital dead or in severe shock. Operative management requires the availability of adequate supplies of type-specific blood, and should include autotransfusion capability if possible. Cardiopulmonary bypass or intravascular shunts may also be needed. All preparations should be completed rapidly because the chances of survival are directly correlated with the length of time between injury and treatment. ${ }^{4}$

In our patient, chest radiography could not show the lesion, but CT at the relevant levels clearly revealed that the tip of the blade had passed over the spine and remained in the aorta. The life-threatening nature of the aortic injury dictated the management of our patient. The patient was hemodynamically stable because of the tamponade effect of the foreign body. Therefore, it was necessary to delay removal of the blade until vascular control had been achieved.

The thoracotomy incision for the treatment of great vessel injuries is chosen according to the site of the entrance wound, and is usually an anterolateral or posterolateral thoracotomy. After a rapid thoracotomy, any active bleeding can be controlled by digital pressure, or partial or total occlusion of the injured vessel. Then, the nature and extent of the injury is determined, and the time required for repair estimated. In most cases, aortic lacerations can be repaired without the aid of cardiopulmonary bypass or shunts. In our case, we were able to repair the vascular defect by primary suturing with proximal and distal clamping lasting for 10 minutes.

The neurosurgical step involved laminectomy, 
exploration, and primary dural closure. We think that this may be beneficial for preventing fistula and infection after the retained knife fragment had been removed in the already anesthetized patient. However, there are no definite indications for neurosurgical intervention as an adjunct to general surgical repair in cases of penetrating spinal injury associated with visceral injury. ${ }^{7}$

In this case, detection of the aortic injury saved the patient from the hazard of fatal hemorrhage. Any signs of a penetrating body passing through the spine should suggest the possibility of visceral injury, and multidisciplinary treatment should be planned.

\section{References}

1) Demetriades D: Penetrating injuries to the thoracic great vessels. J Card Surg 12 (2 Suppl): 173-180, 1997

2) Jacobson SA, Bors E: Spinal cord injury in Vietnamese combat. Paraplegia 7: 263-281, 1970

3) Peacock WJ, Shrosbree RD, Key AG: A review of 450 stabwounds of the spinal cord. S Afr Med J 51:
961-964, 1977

4) Stanley WE, Anderson DJ: Successful surgical management of stab injury of the thoracic aorta with penetration of the spinal cord. J Am Osteopath Assoc 81: 531-534, 1982

5) Thakur RC, Khosla VK, Kak VK: Non-missile penetrating injuries of the spine. Acta Neurochir (Wien) 113: 144-148, 1991

6) Velmahos GC, Degiannis E, Hart K, Souter I, Saadia R: Changing profiles in spinal cord injuries and risk factors influencing recovery after penetrating injuries. J Trauma 38: 334-337, 1995

7) Venger BH, Simpson RK, Narayan RK: Neurosurgical intervention in penetrating spinal trauma with associated visceral injury. J Neurosurg 70: 514-518, 1989

Address reprint requests to: C. Kilincer, M.D., Trakya Üniversitesi Tıp Fakültesi, Nöroşirürji Anabilim Dalı, 22030-Edirne, Turkey. e-mail: ckilincer@trakya.edu.tr, ckilincer@medscape.com 